\title{
Cognitive Decline and Subclinical Atherosclerosis in Patients with Atrial Fibrillation and Vascular Risk Factors
}

\author{
MARIUS MILITARU ${ }^{1}$, MIRCEA IURCIUC ${ }^{2 *}$, STELA IURCIUC ${ }^{2 *}$, DANIEL LIGHEZAN ${ }^{3}$, VLADIANA TURI ${ }^{2 *}$, \\ CLAUDIA VARZOB BALASA ${ }^{4}$, ANDA MILITARU ${ }^{3 *}$, ALEXANDRU CARABA ${ }^{5}$, ADINA CRISTIANA AVRAM ${ }^{3}$, \\ MIHAELA SIMU 1 \\ ${ }^{1}$ Victor Babes University of Medicine and Pharmacy, Department of Neuroscience, Neurology, Emergency City \\ Hospital, Timisoara, 5 Gh. Dima Str., 300254, Romania \\ ${ }^{2}$ Victor Babes University of Medicine and Pharmacy, Department of Cardiology, Discipline of Ambulatory Internal \\ Medicine, Cardiovascular Prevention and Rehabilitation, 49 C.D. Loga Str., 300020, Timisoara, Romania \\ ${ }^{3}$ Victor Babes University of Medicine and Pharmacy, Department of Internal Medicine I, Medical Semiology I, \\ Emergency City Hospital, Timisoara, 5 Gh. Dima Str.,, 300254, Romania \\ ${ }^{4}$ Emergency City Hospital, Timisoara, 5 Gh. Dima Str., 300254, Romania \\ ${ }^{5}$ Victor Babes University of Medicine and Pharmacy, Department of Internal Medicine, 2 Eftimie Murgu Sq., 300041, \\ Timisoara, Romania
}

\begin{abstract}
Recent evidence shows that many vascular risk factors (VRFs) contribute to the cognitive decline. The aim of the study was to evaluate the cognitive decline, depression and the occurrence of subclinical atherosclerosis and the association between cognitive decline and subclinical atherosclerosis in patients with atrial fibrillation (AF) and VRFs versus patients without AF but with VRFs. After statistical analysis, we concluded that cognitive decline is more common in patients with AF and VRFs than in those without AF, but with VRFs, and we consider it is mandatory to identify and prevent cognitive changes. Our findings suggest a direct association between cognitive decline and AF, age, risk factors, cognitive parameters, hemodynamic changes (LVEF) and subclinical atherosclerosis (IMT).
\end{abstract}

Keywords: cognitive decline, atrial fibrillation, vascular risk factors, subclinical atherosclerosis

$\mathrm{AF}$ is one of the most common cardiac arrhythmias with over 6 million people in Europe being diagnosed with this type of arrhythmia. It is estimated that $2.5 \%$ of the world's population has $\mathrm{AF}$ and its prevalence increases substantially with age, especially after the 50 years, and men have a 1.5 times higher risk than women to develop AF [1] .

Patients affected by AF may have a poor quality of life, low functional status and impaired cardiac function. Statistics show that over the next 50 years its prevalence will be at least 2.5 times higher [1]. In patients diagnosed with $\mathrm{AF}$, there is a greater risk to develop stroke or heart failure, and to die more rapidly compared to patients without $\mathrm{AF}[2]$.

$\mathrm{AF}$ can be seen in patients with the following pathologies: valvulopathy, cardiomyopathies, hypertension, heart failure, congenital heart defects, coronary heart disease, obesity, diabetes mellitus, thyroid dysfunction, chronic obstructive pulmonary disease, sleep apnea or chronic kidney disease. It is necessary to establish the correct and genuine diagnosis of AF and the main goal in the management of fibrillation is to prevent its complications [1]. AF is recognized as an independent risk factor for cerebrovascular disease, which may manifest itself as impairment of cognitive function and dementia [3].

It is known that AF will be more and more common, due to the ageing of the population. The increase of elderly patients with AF leads to the occurence and evolution of cognitive disorders in them. Patients with mild cognitive impairment have a lower quality of life compared to patients with normal cognitive function, and these patients have an increased risk of morbidity. Patients diagnosed with dementia have a higher mortality risk than non-dementia patients. The diagnosis of cognitive impairment is based on clinical evaluation and memory test scores, which are closely correlated with the daily functional status of the patient.

More than $20 \%$ of people > 70 years of age have mild cognitive impairment (MCI). Information from the literature shows that there is a close relationship between $\mathrm{AF}$ and stroke in terms of occurrence and progression of cognitive impairment. [2] It is further attempted to establish a close relationship between AF, cognitive decline and dementia, independent of the presence of stroke, by analyzing subclinical atherosclerosis, cardiac performance and neuropsychological tests.

\footnotetext{
*email: mirceaiurciuc@gmail.com; stela_iurciuc@yahoo.com; vladiana@gmail.com; anda28@yahoo.com
} 


\section{Experimental part}

The purpose of our study was to identify the premature cognitive decline using neuropsychological tests and onset of myocardial dysfunction using echocardiographic parameters of left ventricle function (LVEF) and also to detect the earliest signs of subclinical atherosclerosis using arterial parameter (IMT), in patients with AF and VRFs compared with patients without AF and VRFs.

We enrolled a total of 90 patients: 45 patients diagnosed with AF (paroxysmal, persistent or permanent) and VRFs vs. 45 patients without AF but with VRFs, all of them were admitted to internal medicine or neurology clinics. Inclusion criteria were: patients with AF and VRFs with no previous history of cognitive decline or dementia, treated with OACs or NOACs therapy. All standards regarding ethics and good clinical practice were followed throughout our study. For all patients, we performed biochemical analyses, clinical and echocardiographic evaluation, neuropsychological assessment including MMSE, MoCA, ADL, IADL and GDS. The clinical evaluation consisted of: medical history, clinical examination - and the following parameters were registered: heart rate [HR], systolic blood pressure (SBP) and diastolic blood pressure (DBP). The paraclinical assessment consisted of: blood tests, resting electrocardiogram (EKG), transthoracic echocardiography - including left ventricular parameters function and Doppler of the carotid artery and arterial parameters of subclinical atherosclerosis (IMT). AF was determined through cardiac physical examination and electrocardiography at rest, independently of its status: paroxysmal, persistent, or permanent. Cranial computed tomography was performed in selected cases and it was not mandatory cognitive decline diagnosis.

Transthoracic echocardiography was performed using a General Electric Vivid E9 ultrasound system with a $5 \mathrm{MHz}$ transducer, using two-dimensional (2D) methods and transverse sections. Images were obtained in the following views: parasternal long - axis, short-axis of LV and apex, apical long-axis of the 4, 3 and/or 2 chambers. LV performance was assessed by measuring left ventricle ejection fraction (LVEF) using planimetry and calculated according to the formula: LVEF \% = (LVEDD - LVESD) / LVEDD 100 . LV diastolic function was assessed by measuring transmitral flow, Doppler inflow signal in parallel alignment with mitral blood flow, in order to quantify the maximum velocity of early filling wave (E- wave). All echocardiographic examinations were performed by the same examiner and on the same machine.

\section{Parameters of subclinical atherosclerosis}

IMT evaluation was performed using a General Electric Vivid E9 ultrasound system with a linear array transducer of $9 \mathrm{MHz}$. Measurements were obtained in the distal common carotid artery (CCA), $1 \mathrm{~cm}$ from the flow divider, at the far wall level; 10 measurements were performed for each patient and mean values were registered.

\section{Neuropsychological tests \\ Mini-Mental State Examination (MMSE)}

MMSE is a wide indicator used in assessing cognitive function and screening for quantification of cognitive impairment. This parameter includes the study of several types of cognitive functions such as (attention, orientation, calculation, recall, language manipulation, including constructional praxis). The MMSE score is between 0-30 points and when it is below 24 points, it represents a predictor for the onset of cognitive impairment and dementia. The MMSE score can be different depending on the age and educational level of the patient $[3,4]$. This score is often used to identify and analyze the presence of cognitive impairment, and to study the evolution of the cognitive disorders for each individual patient $[3,5]$.

\section{Montreal Cognitive Assessment (MoCA)}

MoCA is a widely used screening assessment for detecting cognitive impairment. The MoCA test is a 30-point test administered in approximately $10 \mathrm{~min}$. The MoCA assesses several cognitive domains: Visuospatial abilities (3 points), the short-term memory recall task (5 points), a three-dimensional cube copy (1 point), a phonemic fluency task ( 1 point), executive functions ( 1 point) and a two-item verbal abstraction task ( 2 points). Concentration, attention, and working memory are evaluated using a sustained attention task (target detection using tapping; 1 point), digits forward and backward (1 point each) and a serial subtraction task (3 points). Language is assessed using a three-item confrontation naming task with low-familiarity animals ( 3 points), the aforementioned fluency task and repetition of two syntactically complex sentences ( 2 points). Orientation to time and place is evaluated by asking the subject for the date and the city in which the test is occurring (6 points) [6]. MoCA is a very effective score in early identification of MCI and early signs of Alzheimer's disease compared to MMSE score. MoCA scores range between 0 and 30. A MoCA score of 26 or over is considered to be normal [6].

Activities of daily living [ADL] ADL is used in the field of healthcare on a very large scale and refers to daily care activities. This indicator is commonly used by healthcare professionals to assess the capacity or person's inability to 
measure their functional status, especially in the elderly, with disabilities or with coronary diseases [7]. The ADL scale takes about $10 \mathrm{~min}$ for administration [8]. As far as these functional abilities are concerned at the beginning of their life, they are well managed by the patient, but with the occurence of cognitive disorders, their performance begins to deteriorate. We used in our study the variation of ADL with 5 basic categories: personal hygiene, dressing, eating, maintaining continence and transferring/mobility. ADL scores are between 0 [reduced functionality] and 10 [high functionality] [7, 8].

\section{Instrumental Activities of Daily Living (IADL)}

Lawton's IADL scale was developed to evaluate more complex activities, such as daily practical activities, which are necessary for normal business functioning [e.g. cooking, financial management or shopping]. These activities are more complex and are lost to patients with cognitive impairment before normal daily activities measured through ADL scale. Using this IADL scale, we identify early cognitive decline in older people with those requiring short-term or long-term care [9]. This Lawton IADL scale requires 10 to $15 \mathrm{~min}$ for evaluation. It can be applied in the form of an interview with the patient, or in the form of a written questionnaire that the patient fills in and contains 8 items with a cumulative score from 0 [low functionality] to 8 [high functionality] [9].

\section{Geriatric Depression Scale (GDS)}

Although there are several methods used to assess depression, Yesavage created GDS that is more useful for the elderly population. This scale contains 30 questions and is utilized to identify depression in elderly. Patients answer these questions by yes or no. [10] For an easier evaluation, a shorter GDS version containing only 15 questions was developed [11]. This shorter version is easier to use and very often applied by medical staff in clinical trials. The shorter version of the GDS is also easily used in patients with cognitive impairment, where a greater number of questions might be difficult to apply. [12] We used this short version for this study. The 15-question GDS scale (GDS$15)$ has a specificity of $89 \%$ and a sensitivity of $92 \%$ for diagnostic criteria of depression $[11,12]$.

Statistical analysis was performed using SPSS program version 20.0. Results are expressed as percentages, mean value \pm standard deviation. Assessment of LV function, vascular parameters, memory tests and the activity of daily living, depression tests, blood tests, HR and blood pressure in both groups of patients were done using impaired T-test. $\mathrm{CHA}_{2} \mathrm{DS}_{2}$-Vasc score and use of OACs or NOACs in AF patients were calculated using paired T-test. The values for $\mathrm{p}$ $<0.001$ and $\mathrm{p}<0.05$ were considered statistically significant.

\section{Results and discussions}

All 90 patients enrolled in our study had a mean age of $69.98 \pm 9.89$ [44 - 89 years]. Among them, $54(60 \%)$ were females with a mean age between $71.26 \pm 9.48$ years and $36(40 \%)$ were men with mean age $68.06 \pm 10.30$ years. 30 (33.3\%) patients were younger than 65 years old and 60 were older than 65 years old $(66,7 \%)$.

45 patients with AF and VRFs had a mean age of $72.84 \pm 9.69$ [49 - 89 years]. Out of the total number, 41 patients (91.1\%) had hypertension, $12(26.7 \%)$ had diabetes mellitus, $24(53.3 \%)$ were with dyslipidemia and $9(20 \%)$ were smokers. (Table 1)

Table 1

PATIENT DEMOGRAPHIC DATA, VASCULAR RISK FACTORS (VRFs)

\begin{tabular}{|c|c|c|c|}
\hline & All 90 patients & $\begin{array}{c}45 \text { patients with AF } \\
\text { and VRFs }\end{array}$ & $\begin{array}{c}45 \text { patients without AF } \\
\text { and with VRFs }\end{array}$ \\
\hline & $\begin{array}{l}\text { No. of patients/ } \\
\text { mean }+/-\mathrm{SD} /[\%]\end{array}$ & $\begin{array}{l}\text { No. of patients/ } \\
\text { mean }+/-\mathrm{SD} /[\%]\end{array}$ & $\begin{array}{l}\text { No. of patients/ } \\
\text { mean }+/-\mathrm{SD} /[\%]\end{array}$ \\
\hline Age & $90 / 69.98+/-9.89$ & $45 / 72.84+/-9.69 / 50$ & $45 / 67.11+/-9.33 / 50$ \\
\hline Sex/Male/age & $36 / 68.06+/-10.30 / 40$ & $17 / 71.41+/-9.76 / 37.8$ & $19 / 65.05+/-10.08 / 42.2$ \\
\hline Sex/Female/age & $54 / 71.26+/-9.48 / 60$ & $28 / 73.71+/-9.72 / 62.2$ & $26 / 68.62+/-8.64 / 57.8$ \\
\hline \multicolumn{4}{|l|}{ Vascular risk factors } \\
\hline Hypertension & $85 / 94.4$ & $41 / 91.1$ & $44 / 97.8$ \\
\hline Diabetes mellitus & $19 / 21.1$ & $12 / 26.7$ & $7 / 15.6$ \\
\hline Dyslipidemia & $50 / 55.6$ & $24 / 53.3$ & $26 / 57.8$ \\
\hline Smoking & $18 / 20$ & $9 / 20$ & $9 / 20$ \\
\hline Peripheral arterial disease & $5 / 5.6$ & $1 / 2.2$ & $4 / 8.9$ \\
\hline Obesity & $10 / 11.1$ & $5 / 11.1$ & $5 / 11.1$ \\
\hline Coronary disease & $36 / 40$ & $20 / 44.4$ & $16 / 35.6$ \\
\hline Heart failure & $38 / 42.2$ & $25 / 55.6$ & $13 / 28.9$ \\
\hline
\end{tabular}




\begin{tabular}{|c|c|c|c|}
\hline $\begin{array}{c}\text { LVEF<50\% / LVEF>50\% } \\
\text { LVEDV>100/LVEDV <100 }\end{array}$ & $\begin{array}{c}11 / 12.2 / 79 / 87.8 \\
9 / 10 / 81 / 90\end{array}$ & $\begin{array}{c}10 / 22.2 / 35 / 77.8 \\
6 / 13.3 / 39 / 86.7\end{array}$ & $\begin{array}{c}1 / 2.2 / 44 / 97.8 \\
3 / 6.7 / 42 / 93.3\end{array}$ \\
\hline CKD & $26 / 43.18+/-17.36 / 28.9$ & $18 / 40$ & $8 / 17.8$ \\
\hline Lacunar stroke & $26 / 28.9$ & $13 / 28.9$ & $13 / 28.9$ \\
\hline Minor stroke & $11 / 12.2$ & $9 / 20$ & $2 / 4.4$ \\
\hline
\end{tabular}

Abbreviations: $L V E F$ - Left ventricle ejection fraction, CKD -chronic kidney disease,

LVEDV - Left ventricle end-diastolic volume

In this study, we noticed a statistically significant increase of parameters in the lipid profile (total cholesterol, LDL-cholesterol and triglycerides) for patients with AF and VRFs compared to patients without AF but with VRFs. $(\mathrm{p}<0.05) \mathrm{Hb}$ and $\mathrm{Ht}$ statistically significant decreased in patients with AF and VRFs compared to patients without AF and with VRFs $(\mathrm{p}<0.05)$. Creatinine increased significantly from $0.92 \pm 0.21 \mathrm{mg} / \mathrm{dl}$ in patients without AF + VRFs to $1.06 \pm 0.26 \mathrm{mg} / \mathrm{dl}$ in patients with AF and VRFs $(\mathrm{p}<0.05)$. INR and PT $(\%)$ significantly diminished in patients with $\mathrm{AF}$ and VRFs compared to patients without $\mathrm{AF}+\mathrm{VRFs}(\mathrm{p}<0.05)$.

The modifications noticed in the other biological parameters did not reach statistical significance in patients with $\mathrm{AF}$ and VRFs compared to patients without AF and VRFs (Table 2).

Table 2

BIOLOGIC PARAMETERS IN ALL PATIENTS AND IN PATIENTS WITH/WITHOUT AF + VRFs

\begin{tabular}{|c|c|c|c|c|}
\hline & All patients & $\begin{array}{l}\text { Patients with AF } \\
\text { and VRFs }\end{array}$ & $\begin{array}{l}\text { Patients without AF } \\
\text { and with VRFs }\end{array}$ & $\mathrm{p}$ \\
\hline & Mean +/- SD & Mean +/- SD & Mean +/- SD & \\
\hline $\begin{array}{c}\text { Total Cholesterol } \\
(\mathrm{mg} / \mathrm{dl})\end{array}$ & $179.97+/-59.91$ & $197.22+/-64.90$ & $162.73+/-49.40$ & 0.006 \\
\hline $\begin{array}{l}\text { LDL Cholesterol } \\
(\mathrm{mg} / \mathrm{dl})\end{array}$ & $126.90+/-51.90$ & $140.00+/-57.90$ & $113.80+/-41.77$ & 0.016 \\
\hline $\begin{array}{l}\text { HDL Cholesterol } \\
(\mathrm{mg} / \mathrm{dl})\end{array}$ & $48.55+/-20.68$ & $46.51+/-13.46$ & $50.60+/-25.98$ & 0.351 \\
\hline $\mathrm{TG}(\mathrm{mg} / \mathrm{dl})$ & $128.11+/-55.14$ & $139.91+/-62.63$ & $116.46+/-44.11$ & 0.043 \\
\hline Hemoglobin (g/dl) & $13.65+/-1.90$ & $12.98+/-1.92$ & $14.32+/-1.65$ & 0.001 \\
\hline Hematocrit (\%) & $40.86+/-5.19$ & $39.26+/-5.54$ & $42.46+/-4.32$ & 0.003 \\
\hline $\operatorname{ESR}(\mathrm{mm} / \mathrm{h})$ & $7.50+/-2.01$ & $7.40+/-2.22$ & $7.60+/-1.78$ & 0.634 \\
\hline $\begin{array}{c}\text { Thrombocytes } \mathrm{x} \\
10^{3} / \mu \mathrm{L}\end{array}$ & $228.38+/-60.36$ & $226.71+/-64.75$ & $230.06+/-56.32$ & 0.794 \\
\hline Glycemia (mg/dl) & $113.94+/-37.46$ & $114.77+/-47.11$ & $113.11+/-24.85$ & 0.834 \\
\hline Creatinine (mg/dl) & $0,99+/-0.25$ & $1.06+/-0.26$ & $0.92+/-0.21$ & 0.009 \\
\hline Urea (mg/dl) & $43.07+/-19.56$ & $46.12+/-23.77$ & $40.02+/-13.77$ & 0.141 \\
\hline $\mathrm{ALT}(\mathrm{U} / \mathrm{L})$ & $28.32+/-20.19$ & $30.22+/-26.86$ & $26.42+/-9.78$ & 0.376 \\
\hline AST (U/L) & $25.40+/-16.93$ & $28.75+/-22.75$ & $22.04+/-6.25$ & 0.062 \\
\hline CKMB (U/L) & $16.95+/-9.02$ & $19.06+/-11.31$ & $14.83+/-5.23$ & 0.026 \\
\hline $\mathrm{Na}(\mathrm{mmol} / \mathrm{l})$ & $140.68+/-2.71$ & $140.77+/-2.96$ & $140.60+/-2.48$ & 0.768 \\
\hline $\mathrm{K}(\mathrm{mmol} / \mathrm{l})$ & $4.11+/-0.45$ & $4.03+/-0.52$ & $4.18+/-0.36$ & 0.131 \\
\hline Uric acid (mg/dl) & $6.15+/-1.61$ & $6.23+/-1.79$ & $6.08+/-1.42$ & 0.667 \\
\hline INR & $1.87+/-0.82$ & $1.67+/-0.91$ & $2.06+/-0.68$ & 0.025 \\
\hline APTT(s) & $27.86+/-7.13$ & $29.15+/-8.78$ & $26.57+/-4.71$ & 0.087 \\
\hline PT (s) & $23.30+/-11.11$ & $21.09+/-11.43$ & $25.51+/ 10.44$ & 0.059 \\
\hline $\mathrm{PT}(\%)$ & $60.58+/-31.65$ & $69.63+/-31.34$ & $51.52+/-29.61$ & 0.006 \\
\hline
\end{tabular}

Abbreviations: LDL - Low-density lipoprotein; HDL - High-density lipoprotein; TG - Triglycerides; ESR - erythrocytes sedimentation rate; AST - Aspartate aminotransferase; ALT-Alanine aminotransferase; CKMB - Creatine kinase MB; Na - Sodium; $K$ - Potassium; INR - International normalized ratio; APTT - Activated partial thromboplastin time; PT - Prothrombin time. 
Using 2D echocardiography in both groups of patients we observed statistically significant modifications of the following parameters: LA $(\mathrm{mm})$ increased from $38.9 \pm 4.8$ in patients without AF to $45.2 \pm 6.5$ in patients with $\mathrm{AF}$ $(\mathrm{p}<0.001)$. LVEF $(\%)$ significantly decreased from 59.08 \pm 5.54 in patients without AF to $55.91 \pm 8.55$ in patients with AF $(p<0.05)$. We observed significant changes in other echocardiographic parameters: LVEDD and PASP increased statistically significant in patients with $\mathrm{AF}$ versus patients without $\mathrm{AF}(\mathrm{p}<0.05)$. From the entire lot of patients, 11 patients $(12.2 \%)$ patients had a LVEF $<50 \%$. Out of the group of patients with AF + VRFs, 10 patients $(22 \%)$ had an LVEF $<50 \%$.

We noticed that changes of LV diastolic dysfunction parameters (analyzed through transmitral flow - E-wave) did not reach statistical significance range in patients with $\mathrm{AF}+\mathrm{VRFs}$ versus patients without AF and VRFs (Table 3).

Table 3

ECHOCARDIOGRAPHIC PARAMETERS IN BOTH GROUPS OF PATIENTS

\begin{tabular}{|c|c|c|c|c|}
\hline & All patients & $\begin{array}{l}45 \text { patients with AF } \\
\text { and with VRFs }\end{array}$ & $\begin{array}{l}45 \text { patients without AF } \\
\text { and with VRFs }\end{array}$ & $\mathrm{P}$ \\
\hline & Mean +/- SD & Mean +/- SD & Mean +/- SD & \\
\hline LA (mm) & $42.1+/-6.5$ & $45.2+/-6.5$ & $38.9+/-4.8$ & $<0.001$ \\
\hline IVS (mm) & $11.7+/-2.0$ & $12.0+/-1.8$ & $11.5+/-2.2$ & 0.289 \\
\hline LVPW (mm) & $11.8+/-2.3$ & $11.3+/-1.7$ & $12.4+/-2.7$ & 0.025 \\
\hline LVEDD (mm) & $46.9+/-5.4$ & $49.2+/-5.6$ & $44.6+/-4.0$ & $<0.001$ \\
\hline LVESD (mm) & $23.7+/-6.5$ & $22.6+/-7.3$ & $24.9+/-5.5$ & 0.096 \\
\hline LVEF (\%) & $57.50+/-7.39$ & $55.91+/-8.65$ & $59.08+/-5.54$ & 0.041 \\
\hline LVESV (ml) & $35.58+/-14.53$ & $37.66+/-16.73$ & $33.51+/-11.76$ & 0.176 \\
\hline LVEDV (ml) & $77.46+/-21.36$ & $79.71+/-23.80$ & $75.22+/-18.61$ & 0.322 \\
\hline PSAP $(\mathrm{mmHg})$ & $40.04+/-11.41$ & $43.66+/-11.53$ & $36.42+/-10.18$ & 0.002 \\
\hline $\mathrm{E}(\mathrm{m} / \mathrm{s})$ & $0.72+/-0.20$ & $0.75+/-0.22$ & $0.69+/-0.17$ & 0.147 \\
\hline
\end{tabular}

Abbreviations: $L A$ - left atrial, IVS - interventricular septum, LVPW - Left ventricular posterior wall, LVEDD - left ventricular end-diastolic diameter, LVESD - left ventricular end-systolic diameter, LVEF - left ventricular ejection fraction, LVESV - left ventricular end-systolic volume, LVEDV - left ventricular end-diastolic volume, PSAP - pulmonary systolic arterial pressure, $E$ - peak early diastolic transmitral flow velocity

Regarding hemodynamic parameters, statistically significant changes were observed in the HR (b/min), it increased from 71,38 $\pm 10,07$ for patients without AF + VRFs to 78,29 $\pm 17,72(\mathrm{p}<0,05)$ in patients with AF + VRFs. SBP and DBP variations reached statistically significant elevations in patients with AF and VRFs compared to patients without $\mathrm{AF}$ and VRFs $(\mathrm{p}<0.05)$. IMT both left and right registered a significant augmentation in patients with AF and VRFs compared to patients without AF and VRFs $t(p<0,05)$ (Table 4).

Table 4

ASSESSMENT OF HEMODYNAMIC PARAMETERS AND IMT IN BOTH GROUPS OF PATIENTS

\begin{tabular}{|c|c|c|c|c|}
\hline & All patients & $\begin{array}{c}\text { Patients with AF } \\
\text { and with VRFs }\end{array}$ & $\begin{array}{c}\text { Patients without AF } \\
\text { and with VRFs }\end{array}$ & $\mathrm{p}$ \\
\hline & Mean \pm SD & Mean \pm SD & Mean \pm SD & \\
\hline HR (b/min) & $74.83 \pm 14.75$ & $78.29 \pm 17.72$ & $71.38 \pm 10.07$ & 0.026 \\
\hline SBP (mmHg) & $132.11 \pm 19.71$ & $137.67 \pm 23.68$ & $126.56 \pm 12.74$ & 0.007 \\
\hline DBP (mmHg) & $78.61 \pm 12.91$ & $82.00 \pm 13.24$ & $75.22 \pm 11.77$ & 0.012 \\
\hline IMT left $(\mathrm{mm})$ & $0.70 \pm 0.32$ & $0.81 \pm 0.31$ & $0.59 \pm 0.30$ & 0.002 \\
\hline IMT right $(\mathrm{mm})$ & $0.68 \pm 0.34$ & $0.81 \pm 0.35$ & $0.56 \pm 0.29$ & $<0.001$ \\
\hline
\end{tabular}

Abbreviations: SD - Standard Deviation, HR - heart rate, SBP - systolic blood pressure, DBP - diastolic blood pressure, IMT - intima-media thickness

MMSE decreased statistically significant from $28.13 \pm 2.55$ to $24.60 \pm 4.55(\mathrm{p}<0.001)$ and MoCA decreased statistically significant from $25.84 \pm 4.45$ to $22.53 \pm 5.05$ ( $\mathrm{p}<0.001)$ in patients with AF and VRFs compared to patients without AF and VRFs. ADL and IADL significant decrease and GDS-15 significant increase in patients with AF and VRFs compared to patients without AF and VRFs ( $\mathrm{p}<0.05)$ (Table ). 
Table 5

NEUROPSYCHOLOGICAL TESTS IN ALL GROUPS OF PATIENTS

\begin{tabular}{|c|c|c|c|c|}
\hline & All patients & $\begin{array}{c}\text { Patients with AF and } \\
\text { with VRFs }\end{array}$ & $\begin{array}{c}\text { Patients without AF and with } \\
\text { VRFs }\end{array}$ & Mean \pm SD \\
\hline & Mean \pm SD & Mean \pm SD & $28.13 \pm 2.55$ & $<0.001$ \\
\hline MMSE & $26.37 \pm 4.09$ & $24.60 \pm 4.57$ & $25.84 \pm 4.45$ & 0.001 \\
\hline MoCA & $24.19 \pm 5.01$ & $22.53 \pm 5.05$ & $9.76 \pm 0.60$ & 0.002 \\
\hline ADL & $9.43 \pm 1.01$ & $9.11 \pm 1.22$ & $7.38 \pm 1.05$ & $<0.001$ \\
\hline IADL & $6.73 \pm 1.65$ & $6.09 \pm 1.89$ & $5.86 \pm 2.21$ & $<0.001$ \\
\hline
\end{tabular}

Abbreviations: SD - Standard Deviation, MMSE - Mini-Mental State Examination Scale; MoCA - Montreal Cognitive Assessment Scale; ADL - Activities of Daily Living Score, IADL - Instrumental Activities of Daily Living Score; GDS-15 -15-question Geriatric depression scale[GDS].

Regarding the age above 65 years, from all the studied patients, 23 patients were with AF and VRFs and 27 patients were without AF and with VRFs. In this study patients MMSE significantly decreased from $27.96+/-4.64$ in patients without AF to $23.79+/-3.03$ in patients with AF and MoCA significantly decreased from $25.81+/-5.15$ in patients without AF to $22.21+/-5.14$ in patients with AF ( $<<0.05$ ). SBP, DBP, IMT left and right and GDS-15 were significantly increased and neuropsychological tests [ADL, IADL] were significantly decreased in patients with AF more than 65 years versus patient without AF more than 65 years. $(\mathrm{p}<0.05)$

Regarding the age of fewer than 65 years, 12 patients were with AF and VRFs and 18 patients without AF and with VRFs. In this 12 study patients with AF less than 65 years, the presence of AF did not influence statistically changes in neuropsychological tests, echocardiographic parameters, IMT or hemodynamic parameters.
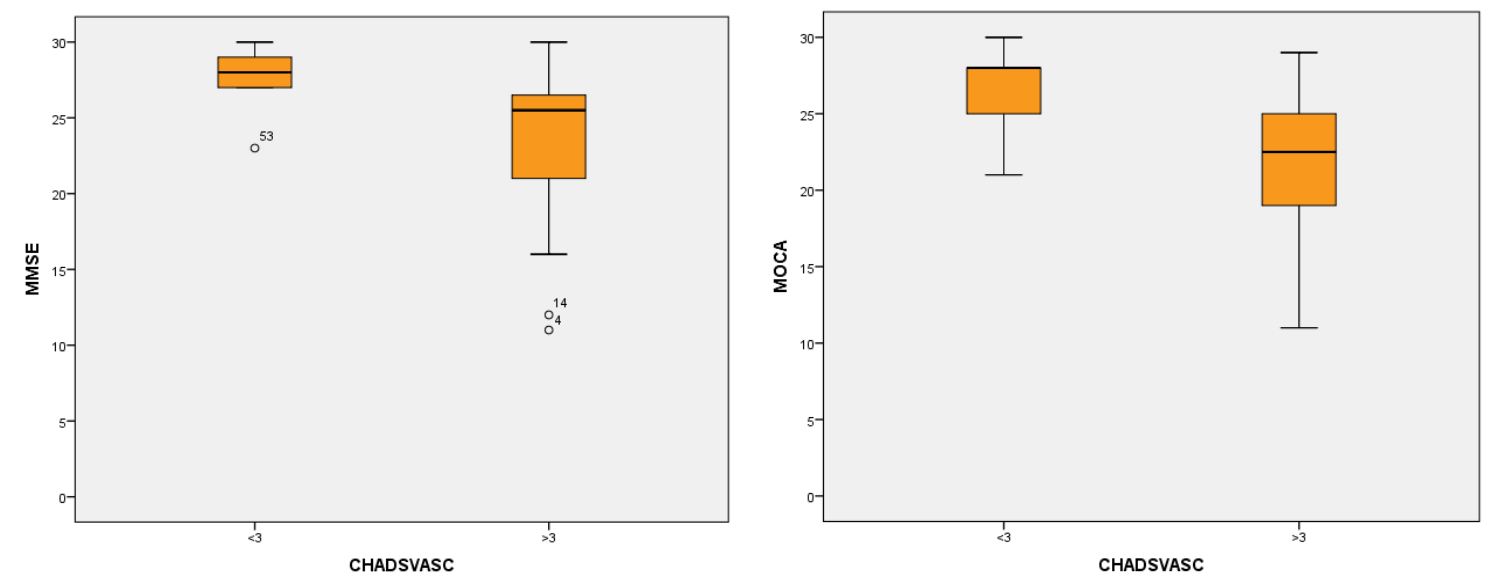

Fig. 1. MMSE and MoCA in patients with $\mathrm{AF}$ and VRFs with $\mathrm{CHA}_{2} \mathrm{DS}_{2}-\mathrm{Vasc}<$ or $>3$

Out of 45 patients with AF and VRFs, 14 patients were with paroxysmal AF, 6 with persistent AF and 25 with permanent AF. $\mathrm{CHA}_{2} \mathrm{DS}_{2}$-Vasc was $3.66+/-1.43$ and HAS-BLED $2.46+/-1.03$ for all patients with AF. From all the patients with AF, 9 [20\%] patients were with $\mathrm{CHA}_{2} \mathrm{DS}_{2}$-Vasc $<3$ (1 or 2) and $36(80 \%)$ patients with $\mathrm{CHA}_{2} \mathrm{DS}_{2}-\mathrm{Vasc}$ $>3$.

MMSE significantly decreased from $27.78+/-2.16$ in patients with $\mathrm{AF}$ and $\mathrm{CHA}_{2} \mathrm{DS}_{2}-\mathrm{Vasc}<3$ compared with patients with $\mathrm{CHA}_{2} \mathrm{DS}_{2}-\mathrm{Vasc}>3$ with MMSE $23.81+/-4.68(\mathrm{p}<0.05)$. MoCA significant decrease from $26.56+/-2.96$ to $21.53+/-4.98$ in patients with $\mathrm{AF}$ and $\mathrm{CHA}_{2} \mathrm{DS}_{2}-\mathrm{Vasc}>3$ compared with patients with $\mathrm{CHA}_{2} \mathrm{DS}_{2}-\mathrm{Vasc}<3$ $(\mathrm{p}<0.05)$. ADL significantly decreased and GDS significantly increased in patients with $\mathrm{AF}$ and $\mathrm{CHA}_{2} \mathrm{DS}_{2}$-Vasc $>3$ compared with patients with $\mathrm{CHA}_{2} \mathrm{DS}_{2}-\mathrm{VASc}<3(\mathrm{p}<0.05)$.

ADL significantly decreased from $9.79+/-0.42$ in patients with paroxysmal AF to $8.81+/-1.35$ in patients with persistent or permanent AF $(\mathrm{p}<0.05)$. There were no differences between other neuropsychological parameters or vascular parameters in patients with different types of $\mathrm{AF}$.

Out of the whole study group of AF patients regarding age, was noticed a significant decreased for both HR, from $87.25 \pm 21.23$ to $75.03 \pm 15.36(\mathrm{p}<0.05)$ and IMT right, from $0.089 \pm 0.029$ to $0.060 \pm 0.041(\mathrm{p}<0.05)$ in patients with $\mathrm{AF}$ age less than 65 versus patients with $\mathrm{AF}$ and age more than 65. Significant deterioration was noticed regarding neuropsychological tests regarding age: MMSE significant decrease from $26.83 \pm 3.66$ to $23.79 \pm 4.63$ ( $\mathrm{p}<0.05)$ and GDS-15 significant increase from $6.33 \pm 2.87$ to $8.15 \pm 1.43$ ( $\mathrm{p}<0.05$ ). 

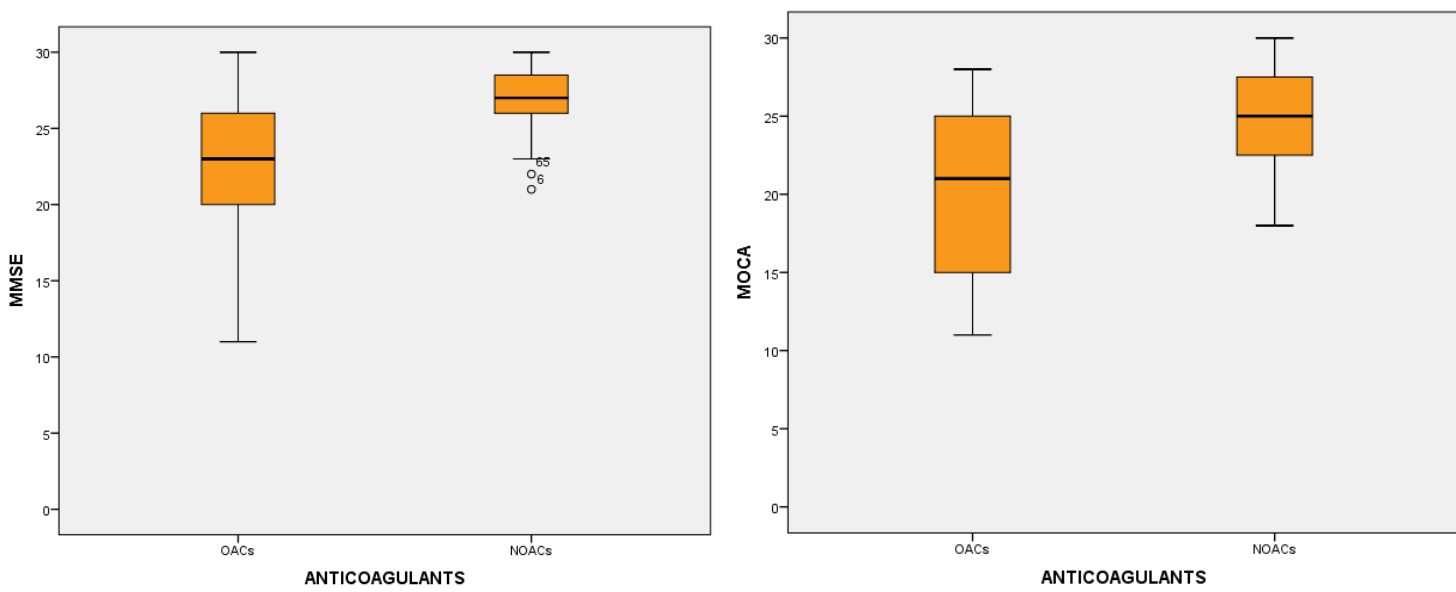

Fig. 2. MMSE and MoCA in patients with AF and VRFs treated with anticoagulants therapy [OACs or NOACs].

All patients with AF were with anticoagulants therapy. 21 patients were with oral anticoagulants using vitamin $\mathrm{K}$ antagonists (VKAs) - acenocoumarol therapy - (OACs) and 24 patients were with non-vitamin $\mathrm{K}$ antagonist oral anticoagulants therapy (NOACs). From that 24 patients on NOACs, $9(10 \%)$ were on apixaban (direct factor Xa inhibitor) therapy, $11(12.2 \%)$ on dabigatran (direct thrombin inhibitor) therapy and 4 (4.4\%) on rivaroxaban (direct factor Xa inhibitor) therapy. MMSE significantly decrease from $26.67+/-2.40$ in patients with AF and NOACs to $22.24+/-5.32$ in patients with AF and OACs therapy. ( $<<0.05$ ) MoCA significantly decreased from 24.88 +/-3.12 in patients with $\mathrm{AF}$ and NOACs to $19.86+/-5.55$ in patients with AF and OACs therapy ( $<<0.05)$. ADL significantly decreased in patients with OACs therapy than patients with NOACs therapy $[\mathrm{p}<0.05]$. IMT and left ventricular parameters diminished without statistically significance for patients with OACs versus NOACs therapy.

Regarding sex, in male patients MMSE significantly decreased from 28.16+/-1.57 for patient without AF to 23.59 +/- 4.90 compared to patients with AF $(\mathrm{p}<0.05)$ and MoCA significantly decreased from $25.21+/-4.15$ in those without AF to $21.53+/-5.30$ vs. patients with AF ( $\mathrm{p}<0.05$ ). ADL and IADL changes were noticed in male patients with $\mathrm{AF}$ and VRFs, with a significant decrease compared to those without AF; HR significantly increased in male patients with $\mathrm{AF}$ versus patients without $\mathrm{AF}(\mathrm{p}<0.05)$.

In female patients with AF and VRFs, we noticed that neuropsychological tests significantly changed: MMSE, MoCA, ADL, IADL significantly decreased and GDS-15 significantly increased compared to female patients without AF $(p<0.05)$. SBP and DBP significantly increased in female patients with AF versus female patients without AF ( $\mathrm{p}<0.05$ ). IMT left and right significantly increased from $0.059+/-0.030$ (IMT left) respectively $0.054+/-0.028$ (IMT right) in female patients without AF to $0.084+/-0.030$ (IMT left) respectively $0.083+/-0.034$ [IMT right] in female patients with $\mathrm{AF}(\mathrm{p}<0.05)$.

Several findings have been revealed in this study. Regarding hemodynamic parameters HR (b/min), SBP (mm Hg) and DBP $(\mathrm{mm} \mathrm{Hg})$ variations reach statistical significant increase in patients with AF and VRFs, compared to patients without AF and with VRFs ( $\mathrm{p}<0.05$ ). In the AFFRIM (Atrial Fibrillation Follow-Up Investigation of Rhythm Management) study, in post-hoc analysis of 3947 patients, there was an increase of $10 \mathrm{~mm} \mathrm{Hg}$ in SBP and DBP from baseline. These data suggest that in patients with AF, the optimal BP target may be higher than the general population and the medication for treating AF can be associated with adverse events or all-cause mortality if BP is reduced to $<110 / 60 \mathrm{mmHg}$ [13].

Hypertension is an extremely important risk factor and can be a predictor for AF development. The combination of hypertension and AF will be more common in the future due to the increasing population prevalence of both conditions [14]. From all our study patients, 85 (94, 4\%) were with hypertension, and from all AF patients, 41 were hypertension, 14 patients were with paroxysmal $\mathrm{AF}$ and 31 with persistent or permanent AF. Hypertension was found to be predictive of arrhythmia progression from paroxysmal to persistent or permanent AF. [14] In European Heart Survey, during the 1-year follow-up, hypertension was more common in those who developed persistent or permanent AF versus paroxysmal AF patients ( $71 \%$ vs. $60 \%, \mathrm{HR} 1.52,95 \%$ confidence interval [CI] 1.05-2.20) [15]. One of the major components of AF management to improve patient outcomes is to optimize BP control. [14] In the RECORDAF study (odds ratio 1.5, 95\% CI 1.1-2.0), a prospective survey on AF management, this was further confirmed [16].

Patients with AF may experience reduced LVEF. [17] In our study, we observed statistically modifications of LVEF (\%) with 3\% significant decreased in patients with AF and VRFs and the values were between $47-63 \%$ $(\mathrm{p}<0.05)$. From the patients with AF and VRFs, 10 patients $(22 \%)$ registered LVEF $<50 \%$. In a study involving 385 adults with newly diagnosed AF, patients who had AF and LVEF $<55 \%$ at the beginning were associated with longer- 
term mortality of all causes. Those who subsequently recovered LVEF after medical therapy appears to have similar prognosis compared to those with LVEF > 55\% initially [17].

The ARIC-NCS study (Atherosclerosis Risk in Communities Neurocognitive Study) analysed 6432 patients, of whom 611 (9.5\%) had AF. AF was associated with an increased rate of MCI and dementia (CI 95\%, 1.28, 1.04-1.562, respectively 2.5, 1.64-3.10). The prevalence of MCI / vascular dementia and MCI / dementia associated with Alzheimer's disease was higher in patients with AF than without AF (95\% CI, 1.50, 0.99-2.25 and 1.29, $1.04-1.61)$. In multivariate analysis, lower body mass index, diabetes mellitus, older age and stroke were associated with the prevalence of dementia in patients with AF [18].

In patients without the manifest atherosclerotic disease, atherosclerosis is an independent risk factor for AF. [19] In our study IMT both left and right registered a significant increase at patients with AF and VRFs compared to patients without AF and VRFs t ( $\mathrm{p}<0.05)$, with no significant changes between men or women. In another study, the risk of AF was associated with IMT (relative risk, 1.90; 95\% CI, 1.20 -3.00) and severity of carotid plaques (relative risk, 1.49; 95\% CI, 1.06-2.10). Risk estimates were stronger in women than in men. These results suggest that the correct treatment of asymptomatic atherosclerosis can prevent AF [19].

In a study included patients with amnestic MCI (an MCI) compared to controls, patients with an MCI were significantly older and had higher rates of AF, hypertension, depression and a larger IMT. [20] In another study on AF patients, young patients without risk factors and cardiac disease, AF was significantly associated with high carotid IMT and carotid-femoral pulse wave velocity [21]. IMT and / or atherosclerosis can be easily detected without risk and at low cost and can be incorporated into existing risk scores for AF to enhance their predictive precision. By preventing $\mathrm{AF}$ and atherosclerosis, cognitive disorders can also be prevented [22, 23].

In our study ADL and IADL significantly decreased and GDS significantly increased in patients with AF and VRFs compared to patients without AF and with VRFs ( $p<0.05)$. The precision of the IADL scale is sensible even when patients experience $\mathrm{MCI}$, while the accuracy of the ADL scale is higher when patients experience more severe cognitive impairment and dementia [24, 25]. Depression is associated with a substantial reduction in quality of life [26]. Depression can be seen more often with ageing. Both major and minor depressions were found in $13 \%$ of the elderly population. It has also been reported in $24 \%$ of older patients with medical pathology and $43 \%$ of patients requiring acute or chronic medical care at home [10]. The relationship between depression and MCI is complex. While a meta-analysis identifies depression as a risk factor for MCI [27], other studies evaluating depression and MCI, have found an association with prevalence but not incidence. These findings suggest that depression accompanies MCI but does not precede it [28]. Depression should not be considered as normal in the elderly, it should be recognized and treated as promptly as possible, if it is not treated in time, it can lead to social, physical or cognitive disorders [10].

In a meta-analysis, it has been shown that $\mathrm{AF}$ is associated with increased risk of MCI and dementia, whether or not the patients have a history of stroke [29]. In our study from the AF patients, 13 [28.9\%] had lacunar infarcts and 9 [20\%] minor stroke. In a study that tracked 707 patients after an ischemic stroke, AF was independently associated with lower MMSE scores, thus being associated with a higher risk of developing MCI (odds ratio 1.6, 95\% CI 1.03$2.47, \mathrm{P}=0.03$ ) [30] AF has an increased risk of TIA or stroke, as well as the occurrence of cognitive decline and dementia, whether or not the patient has cerebral vascular pathology [31]. In order to follow the association between the occurrence of cognitive decline and AF, several mechanisms have been identified: micro-lesions, proinflammatory conditions, silent cerebral ischemia [SCI] and altered cerebral blood flow dynamics [32].

As for patients with non-stroke AF, in a study involving 5150 participants, of whom $552(10.7 \%)$ had AF on a 7year follow-up period, cognitive impairment occurred more quickly in AF patients than in non-AF patients. Patients with AF have a higher risk of developing cognitive impairment at younger ages than patients with no history of AF. In patients over 75 years of age who developed $\mathrm{AF}$ compared to those without $\mathrm{AF}$, there was a decrease of about 3 points on the cognitive decline scale as the age increased from 5 to 5 years [33].

In more than half of the 27 articles evaluated in a metathesis, in patients after a stroke, it was highlighted that age, educational level, diabetes, hypertension, type, size, and stroke are significant risk factors for MCI. Of the emotional disturbances presented, the symptoms of depression seem to have an important effect on cognitive disorders. These results are beneficial in addressing the strategy of preventing and managing cognitive impairment in patients after a stroke [34].

From studies comparing patients with $\mathrm{AF}$ versus patients without $\mathrm{AF}$, contain the most important evidence of the relationship between AF and cognitive decline [35]. In our study MMSE and MoCA decreased statistically significant in patients with AF and VRFs compared to patients without AF and VRFs. ( $p<0.001)$ In other studies conducted in Europe and the US, AF prevalence was closely associated with an MCI and global impairment of cognitive function. [36,37] In a study in Germany on detailed cognitive assessments, a group of patients without stroke, of whom 122 patients with AF versus 564 without AF, revealed that patients with AF showed significantly lower performance in terms of memory, learning, and executive functions [38]. 
The Rotterdam Study, which included 6548 participants over the age of 55 years, was among the first studies to highlight an association between AF and cognitive impairment, with the prevalence of dementia being more than double among AF patients compared to non-AF patients. The association was greater in patients less than 65 years of age and more common in females. [39] In the study of the Cardiovascular Health Study, which followed patients for a period of 7 years, the occurrence of AF was associated with the faster occurrence of cognitive impairment by lowering the MMSE score [40].

In our study, ADL significantly decreased in patients with paroxysmal AF, compared with patients with persistent or permanent $\mathrm{AF}(\mathrm{p}<0.05)$. In our patients with $\mathrm{AF}$, patients with persistent or permanent $\mathrm{AF}$ were more than double than patients with paroxysmal AF. There were no differences between other neuropsychological parameters or vascular parameters in patients with different types of AF. Interestingly, in the ARIC (US-based Atherosclerosis Risk in Communities) study, which included 325 patients who had detailed cognitive tests and were monitored for heart rate for up to 14 days, only persistent $\mathrm{AF}$ and not paroxysmal $\mathrm{AF}$ is associated with modifying cognitive function. These findings suggest that maintaining AF over time can lead to changes in patients' cognitive function [41].

There have been studies that have shown that AF can lead to transient or chronic cerebral hypoperfusion by changes in heart rate, blood pressure, and cardiac output [42]. In one study, AF patients were divided by HR in those with low HR $(<50 \mathrm{bpm})$, medium $(50-90 \mathrm{bpm})$ and high $(>90 \mathrm{~b} / \mathrm{min})$. In terms of cerebral hypoperfusion, low and high HR patients presented a higher risk of developing dementia than patients who presented medium HR. The effects of cerebral hypoperfusion due to AF association and heart failure may lead to an increase in cognitive impairment and dementia [43]. BP in large arteries at the base of the brain is considered to be greater than BP in the subcortical microvascularization. Cerebral infusion occurs predominantly during diastole, so low diastolic pressures may increase the risk of small subcortical infarctions that could lead to the role of cognitive disorders [44].

If $\mathrm{AF}$ patients are at greater risk of dementia, it is very important to know and understand all the factors that determine the cognitive impairment in these patients with AF in order to intervene promptly and to prevent the complications of cognitive impairment in patients with this arrhythmia [45].

From all patients with AF, 9 (20\%) patients were with $\mathrm{CHA}_{2} \mathrm{DS}_{2}-\mathrm{VASc}<3(1$ or 2$)$ and $36(80 \%)$ patients with $\mathrm{CHA}_{2} \mathrm{DS}_{2}$-VASc $>3$. MMSE and MOCA significantly decreased in patients with AF and $\mathrm{CHA}_{2} \mathrm{DS}_{2}$-VASc $<3$ compared with patients with $\mathrm{CHA}_{2} \mathrm{DS}_{2}-\mathrm{VASc}>3(\mathrm{p}<0.05)$. ADL significantly decreased and GDS- 15 significantly increased in patient with $\mathrm{AF}$ and $\mathrm{CHA}_{2} \mathrm{DS}_{2}-\mathrm{VASc}>3$ compared with patients with $\mathrm{CHA}_{2} \mathrm{DS}_{2}-\mathrm{VASc}<3(\mathrm{p}<0.05)$. It was found that the higher the CHA2DS2-VASc score, the anticoagulation regimens should be carefully thought to prevent cognitive impairment $[46,47]$. Old age is a very important risk factor for dementia, but also an important component in calculating the CHA2DS2-VASc score [45]. Closer control of the risk factors included in the CHA2DS2-VASc score could lead to good prevention of development disorders cognitive function in patients with AF. In the ARIC-NCS study, it was revealed that higher $\mathrm{CHA}_{2} \mathrm{DS}_{2}-\mathrm{VASc}$ and HAS-BLED, HR, troponin T and higher LV mass index, male sex and low renal function were significantly associated with the occurrence of a higher number of MCI disorders or dementia [18].

In patients with $\mathrm{AF}$, current guidelines recommend anticoagulant treatment to prevent stroke. Thus, using anticoagulant treatment should reduce the risk of cognitive impairment, with the risk of stroke decrease. [48] In our study, all patients with AF were with anticoagulants therapy. 21 patients were with OACs and 24 patients were with NOACs. From that 24 patients on NOACs, $9(10 \%)$ were on apixaban therapy, $11(12.2 \%)$ on dabigatran therapy and 4 (4.4\%) on rivaroxaban therapy. A study involving 973 elderly AF patients after 33 months of follow-up found statistically insignificantly the occurrence of cognitive decline more severely in aspirin-treated patients than in warfarin-treated patients [49]. Particularly in patients who are at increased risk, e.g. patients who have a cognitive decline but not only, a better control of anticoagulant treatment could be particularly effective. In AF patients, understanding the mechanisms of production and accentuation of cognitive decline and dementia could identify more accurate prevention strategies [50]. Oral anticoagulation is a very important treatment for patients with AF [51]. Due to the hypercoagulable state of $\mathrm{AF}$, applying an appropriate anticoagulant therapy can prevent or delay the development of cognitive impairment in $\mathrm{AF}$ patients [52]. In patients with $\mathrm{AF}$, anticoagulation therapy may increase the risk of developing microbleeds, but also may increase the impact on existing ones, which has an effect on cognitive function [52].

In our study MMSE, MOCA and ADL significantly decreased in patients with AF and NOACs compared with patients with AF and OACs therapy $(\mathrm{p}<0.05)$. One study found that patients using OACs had a higher prevalence and incidence of microbleeds. The risk of microbleeds was greater among the patients that showed greater variability in the control of anticoagulation [53]. In our study IMT and left ventricular parameters decrease but not statistically significant in a patient with OACs versus NOACs therapy. The association between AF and MCI can be due to the relatively frequent presence of microbleeds that can lead to cerebral hemorrhage, lacunar infarcts, and cerebral neurodegenerative changes [54]. The use of NOACs would be good for the management of risk factors, as the prognosis of stroke associated with AF is greater than stroke in non-AF patients [55]. Cognitive decline is associated 
with SCI, and patients with AF have higher rates of SCI than patients without AF. The impact of anticoagulation on SCI remains unknown.

In a study, patients with OACs treatment who had a low percentage of maintenance within the optimal therapeutic range, had a higher risk of developing dementia, due to their long period of time when they were out of the optimal interval coagulation. There is currently insufficient data to prove that inappropriate anticoagulation may be involved in the development of cognitive impairment and dementia. We cannot prove whether a person with MCI when is diagnosed with $\mathrm{AF}$ and is being administered anticoagulant treatment, it may increase the risk of dementia [51].

A recent analysis of the risk of dementia in patients diagnosed with AF who received warfarin or non-vitamin $\mathrm{K}$ oral anticoagulants (NOAC) showed that there is a lower risk of dementia among patients receiving NOAC than those who received warfarin [51]. To date, there is insufficient evidence of anticoagulant treatment and its effect on the development of cognitive impairment, there are ongoing clinical trials that take into account the effectiveness of anticoagulation and the improvement of the quality of anticoagulation [51,56].

Some studies have shown that dietary intervention and more adequate BP control can prevent AF, but it is not known yet whether these measures could reduce the risk of cognitive decline and dementia $[57,58]$.

\section{Conclusions}

It is important to know that cognitive decline occurs more frequently in patients with $\mathrm{AF}$ than those without $\mathrm{AF}$, due to the association of cognitive decline with fibrillation, atherosclerosis, age or other cardiovascular risk factors. The more we manage to get better control of cardiovascular risk factors, to prevent cardiovascular disease, atherosclerosis, and to treat AF properly, we can basically prevent cognitive impairment in patients with AF. Dementia is a very important disease with psycho-social impact, so it is important to recognize it from the earliest signs and to act in a timely manner so that it can be avoided. In the future, from clinical trials are needed as much information as possible about the link between anticoagulation and cognitive decline in patients with AF to try to identify the first signs of cognitive decline and to prevent them from evolution.

\section{References}

1.KIRCHHOF P, BENUSSI S, KOTECHA D, AHLSSON A, ATAR D, CASADEI B, CASTELLA M, DIENER HC, HEIDBUCHEL H, HENDRIKS J, HINDRICKS G, MANOLIS AS, OLDGREN J, POPESCU BA, SCHOTTEN U, VAN PUTTE B, VARDAS P, ESC Scientific Document Group, ESC Guidelines for the management of atrial fibrillation developed in collaboration with EACTS, Eur Heart J., 37, no.38, 2016, p.2893-2962.

2. CAO L, POKORNEY SD, HAYDEN K, WELSH-BOHMER K, NEWBY LK, Cognitive Function: Is There More to Anticoagulation in Atrial Fibrillation Than Stroke? J Am Heart Assoc, 4, no.8, 2015, e001573

3.JOZWIAK A, GUZIK P, MATHEW A, WYKRETOWICZ A, WYSOCKI H. Association of atrial fibrillation and focal neurologic deficits with impaired cognitive function in hospitalized patients $>$ or $=65$ years of age, Am J Cardiol, 98, no.9, 2006, p.1238-41

4.PANGMAN VC, SLOAN J, GUSE L, An examination of psychometric properties of the mini-mental state examination and the standardized mini-mental state examination: implications for clinical practice, Appl Nurs Res., 13, no.4, 2000, p.209-13

5. TUIJL, JP; SCHOLTE, EM; DE CRAEN, AJM; VAN DER MAST, RC, Screening for cognitive impairment in older general hospital patients: comparison of the six-item cognitive test with the Mini-Mental Status Examination, International Journal of Geriatric Psychiatry, 27, no.7, 2012, p. 755-762

6. NASREDDINE ZS, PHILLIPS NA, BÉDIRIAN V, CHARBONNEAU S, WHITEHEAD V, COLLIN I, CUMMINGS JL, CHERTKOW H, The montreal cognitive assessment, MoCA: a brief screening tool for mild cognitive impairment, J Am Geriatr Soc., 53, no.4, 2005, p.695-9

7. NOELKER, LINDA, BROWDIE, RICHARD, Sidney Katz, MD: a new paradigm for chronic illness and long-Term care, Gerontologist, 54, no.1, 2014, p.13-20

8. KRISTINE KRAPP, Activities of Daily Living Evaluation, The Gale encyclopedia of nursing \& allied health, Gale Group, Inc., Detroit, 2002 9. GRAF C, The Lawton instrumental activities of daily living scale, Am J Nurs., 108, no.4, 2008, p.52-62

10. YESAVAGE JA, BRINK TL, ROSE TL, LUM O, HUANG V, ADEY M, et al., Development and validation of a geriatric depression screening scale: a preliminary report, J Psychiatr Res., 17,1982, p.37-49

11. SHEIKH JI, YESAVAGE JA, Geriatric Depression Scale [GDS]: recent evidence and development of a shorter version, Clin Gerontol, 5, no. 1/2, 1986, p.165-173

12. LESHER EL, BERRYHILL JS, Validation of the Geriatric Depression Scale-Short Form among inpatients, J Clin Psychol, 50, no.2, 1994, p.256-60

13. BADHEKA AO, PATEL NJ, GROVER PM, SHAH N, PATEL N, SINGH V, DESHMUKH AJ, MEHTA K, CHOTHANI A, SAVANI GT, ARORA S, RATHOD A, MARZOUKA GR, LAFFERTY J, MEHTA JL, MITRANI RD, Optimal blood pressure in patients with atrial fibrillation [from the AFFIRM Trial], Am J Cardiol, 114, no.5, 2014, p.727-36

14. DZESHKA MS, SHAHID F, SHANTSILA A, LIP GYH, Hypertension and Atrial Fibrillation: An Intimate Association of Epidemiology, Pathophysiology, and Outcomes. Am J Hypertens., 30, no.8, 2017, p.733-755

15. DE VOS CB, PISTERS R, NIEUWLAAT R, PRINS MH, TIELEMAN RG, COELEN RJ, VAN DEN HEIJKANT AC, ALLESSIE MA, CRIJNS HJ, Progression from paroxysmal to persistent atrial fibrillation, J Am Coll Cardiol, 55, 2010, p.725-731

16. DE VOS CB, BREITHARDT G, CAMM AJ, DORIAN P, KOWEY PR, LE HEUZEY JY, NADITCH-BRULE L, PRYSTOWSKY EN, SCHWARTZ PJ, TORP-PEDERSEN C, WEINTRAUB WS, CRIJNS HJ, Progression of atrial fibrillation in the REgistry on Cardiac rhythm disORDers assessing the control of Atrial Fibrillation cohort: clinical correlates and the effect of rhythm-control therapy, Am Heart J, 163, 2012, p.887-893. 
17. BENJAMIN MM, CHADDHA A, SAMPENE E, FIELD ME, RAHKO PS, Comparison of Outcomes of Atrial Fibrillation in Patients With Reduced Versus Preserved Left Ventricular Ejection Fraction, Am J Cardiol., 118, no.12, 2016, p.1831-1835

18. ALVARO ALONSO, DAVID S. KNOPMAN, REBECCA F. GOTTESMAN, ELSAYED Z. SOLIMAN, AMIT J. SHAH, WESLEY T. O'NEAL, FAYE L. NORBY, THOMAS H. MOSLEY, LIN Y. CHEN, Correlates of Dementia and Mild Cognitive Impairment in Patients With Atrial Fibrillation: The Atherosclerosis Risk in Communities Neurocognitive Study [ARIC-NCS], J Am Heart Assoc., 6, 2017 , e006014.

19. JAN HEERINGA, DEIRDRE A. M. VAN DER KUIP, ALBERT HOFMAN, JAN A. KORS, FRANK J. A. VAN ROOIJ, GREG Y., H. LIP, JACQUELINE C. M. WITTEMAN, Subclinical Atherosclerosis and Risk of Atrial Fibrillation The Rotterdam Study, Arch Intern Med., 167, no.4, 2007, p.382-387

20. IGNACIO CASADO NARANJOA, JUAN CARLOS PORTILLA CUENCA, BEATRIZ DUQUE DE SAN JUANA, ALFONSO FALCON GARCIA, RAUL ROMERO SEVILLAA, ANA SERRANO CABRERAA, CARMEN CAMARA HIJONB, SILVIA ROMERO CHALAB, JOSE MANUEL FUENTESC AND JOSE MARIA RAMIREZ MORENOD, Association of Vascular Factors and Amnestic Mild Cognitive Impairment: A Comprehensive Approach, Journal of Alzheimer's Disease, 44, 2015, p.695-704

21. CHEN LY, FOO DC, WONG RC, et al., Increased carotid intima-media thickness and arterial stiffness are associated with lone atrial fibrillation, Int J Cardiol., 168, no.3, 2013, p.3132e4.

22. SCHNABEL RB, SULLIVAN LM, LEVY D, et al., Development of a risk score for atrial fibrillation [Framingham Heart Study]: a community-based cohort study, Lancet, 373, no.9665, 2009, p.739e45.

23. KARIN WILLEIT, STEFAN KIECHL, Atherosclerosis and atrial fibrillation - Two closely intertwined diseases, Atherosclerosis, 233, no.2, 2014, p.679-81

24.CAHN-WEINER, D. A., FARIAS, S. T., JULIAN, L., HARVEY, D. J., KRAMER, J. H., REED, B. R., \& CHUI, H., Cognitive and neuroimaging predictors of instrumental activities of daily living, Journal of the International Neuropsychological Society, 13, no.05, 2007, p.747-757

25. MiCHELlE E. MLINAC, MiCHELlE C. FENG, Assessment of Activities of Daily Living, Self-Care, and Independence, Arch Clin Neuropsychol., 31, no.6, 2016, p.506-16

26. ELENA AMARICAI, DAN V. POENARU, The post-stroke depression and its impact on functioning in young and adult stroke patients of a rehabilitation unit, J Ment Health, 25, no.2, 2016, p.137-41

27. STEENLAND K, KARNES C, SEALS R, CARNEVALE C, HERMIDA A, LEVEY A, Late-life depression as a risk factor for mild cognitive impairment or Alzheimer's disease in 30 US Alzheimer's disease centers, J Alzheimers Dis. 31[2], 2012, p.265-75

28. RICHARD E, REITZ C, HONING LH, SCHUPF N, TANG MX, MANLY JJ, MAYEUX R, DEVANAND D, LUCHSINGER JA, Late-life depression, mild cognitive impairment, and dementia, JAMA Neurol., 70, no.3, 2013, p.374-82

29. KALANTARIAN S, STERN TA, MANSOUR M, RUSKIN JN, Cognitive impairment associated with atrial fibrillation: a meta-analysis, Ann Intern Med., 158, no.5 Pt 1, 2013, p.338-46

30. MIZRAHI EH, WAITZMAN A, ARAD M, ADUNSKY A, Atrial fibrillation predicts cognitive impairment in patients with ischemic stroke, Am J Alzheimers Dis Other Demen, 26, no.8, 2011, p.623-6

31. DE BRUIJN, R. F. et al. Association Between Atrial Fibrillation and Dementia in the General Population, JAMA Neurol. 72, no.11, 2015, p.1288-94

32. HUI, D. S., MORLEY, J. E., MIKOLAJCZAK, P. C. \& LEE, R., Atrial fibrillation: A major risk factor for cognitive decline, Am Heart J, 169, no.4, 2015, p.448-56

33. EVAN L. THACKER, BARBARA MCKNIGHT, BRUCE M. PSATY, W.T. LONGSTRETH, JR., HCOLLEEN M. SITLANI, SASCHA DUBLIN, ALICE M. ARNOLD, ANNETTE L. FITZPATRICK, REBECCA F. GOTTESMAN, D SUSAN, R.HECKBERT, Atrial fibrillation and cognitive decline, A longitudinal cohort study, Neurology, 81, no.2, 2013, p.119-125

34. MOHD ZULKIFLY MF, GHAZALI SE, CHE DIN N, SINGH DK, SUBRAMANIAM P, A Review of Risk Factors for Cognitive Impairment in Stroke Survivors, ScientificWorldJournal, 2016, 2016, p.3456943

35. ALONSO A, ARENAS DE LARRIVA AP., Atrial Fibrillation, Cognitive Decline And Dementia, Eur Cardiol., 11, no.1, 2016, p.49-53

36. CASADO NARANJO I, PORTILLA CUENCA JC, DUQUE DE SAN JUAN B, et al., Association of vascular factors and amnestic mild cognitive impairment: a comprehensive approach, J Alzheimers Dis, 44, 2015, p.695-704

37. ALOSCO ML, SPITZNAGEL MB, SWEET LH, et al., Atrial fibrillation exacerbates cognitive dysfunction and cerebral perfusion in heart failure, Pacing Clin Electrophysiol, 38, 2015, p.178-86

38. KNECHT S, OELSCHLÄGER C, DUNING T, et al., Atrial fibrillation in stroke-free patients is associated with memory impairment and hippocampal atrophy, Eur Heart J, 29, 2008, p.2125-32.

39. OTT A, BRETELER MMB, DE BRUYNE MC, et al. Atrial fibrillation and dementia in a population-based study: the Rotterdam Study. Stroke, 28, 1997, p.316-21

40. THACKER EL, MCKNIGHT B, PSATY BM, et al., Atrial fibrillation and cognitive decline: a longitudinal cohort study, Neurology, 81, 2013, p.119-25

41. CHEN LY, AGARWAL SK, NORBY FL, et al., Persistent but not paroxysmal atrial fibrillation is independently associated with lower cognitive function: the Atherosclerosis Risk in Communities [ARIC] Study, J Am Coll Cardiol, 67, 2016, p.1379-80.

42. RIVARD L, KHAIRY P, Mechanisms, Clinical Significance, and Prevention of Cognitive Impairment in Patients with Atrial Fibrillation, Can J Cardiol., 33 no.12, 2017, p.1556-1564

43. ALOSCO ML, SPITZNAGEL MB, SWEET LH, et al., Atrial fibrillation exacerbates cognitive dysfunction and cerebral perfusion in heart failure, Pacing Clin Electrophysiol, 38, 2015, p.178-86

44. BLANCO PJ, MULLER LO, SPENCE JD, Blood pressure gradients in cerebral arteries: a clue to pathogenesis of cerebral small vessel disease, Stroke Vasc Neurol, 2, 2017, p.108-17

45. ALONSO A, ARENAS DE LARRIVA AP, Atrial Fibrillation, Cognitive Decline And Dementia, Eur Cardiol., 11, no.1, 2016, p.49-53

46. LIAO JN, CHAO TF, LIU CJ, et al., Risk and prediction of dementia in patients with atrial fibrillation-a nationwide population-based cohort study, Int J Cardiol., 199, 2015, p.25-30

47. BALL J, CARRINGTON MJ, STEWART S, on behalf of the SAFETY investigators, Mild cognitive impairment in high-risk patients with chronic atrial fibrillation: a forgotten component of clinical management?, Heart, 99, 2013, p.542-547

48. JANUARY CT, WANN LS, ALPERT JS, et al., 2014 AHA/ACC/HRS guideline for the management of patients with atrial fibrillation: a report of the American College of Cardiology/American Heart Association Task Force on Practice Guidelines and the Heart Rhythm Society, Circulation, 130, 2014, p.e199-e267 
49. MAVADDAT N, ROALFE A, FLETCHER K, et al. Warfarin versus aspirin for prevention of cognitive decline in atrial fibrillation: randomized controlled tiral [Birmingham Atrial Fibrillation Treatment of the Aged Study]. Stroke, 45, 2014, p.1381-1386

50. CAMM AJ, KIRCHHOF P, LIP GYH, et al. Guidelines for the management of atrial fibrillation, Eur Heart J., 31, 2010, p.2369-2429

51. JACOBS V, WOLLER SC, STEVENS SM, et al. Percent time with a supratherapeutic INR in atrial fibrillation patients also using an antiplatelet agent is associated with long-term risk of dementia, J Cardiovasc Electrophysiol, 26, 2015, p.1180-1186

52. KALANTARIAN S, RUSKIN JN. Atrial fibrillation and cognitive decline: phenomenon or epiphenomenon? Cardiol Clin., 34, 2016, p.279285

53. AKOUDAD S, DARWEESH SK, LEENING MJ, et al., Use of coumarin anticoagulants and cerebral microbleeds in the general population, Stroke., 45, 2014, p.3436-3439

54. POELS MM, VERNOOIJ MW, IKRAM MA, et al., Prevalence and risk factors of cerebral microbleeds: an update of the Rotterdam scan study, Stroke, 41, 2010, p.S103-S106

55. MARTINEZ C, KATHOLING A, FREEDMAN SB, Adverse prognosis of incidentally detected ambulatory atrial fibrillation. A cohort study, Thromb Haemost, 112, 2014, p.276-286

56. JACOBS V, MAY HT, BAIR TL, et al., Long-term population-based cerebral ischemic event and cognitive outcomes of direct oral anticoagulants compared with warfarin among long-term anticoagulated patients for atrial fibrillation, Am J Cardiol., 2016, 118, no.2, p.210-4

57. MARTINEZ-GONZALEZ MA, TOLEDO E, ARÓS F, et al., Extra-virgin olive oil consumption reduces risk of atrial fibrillation: the PREDIMED trial, Circulation, 130, 2014, p.18-26

58. CHEN LY, BIGGER JT, HICKEY KT, et al., Effect of intensive blood pressure lowering on incident atrial fibrillation and p-wave indices in the ACCORD Blood Pressure Trial, Am J Hypertens, 29, no.11, 2016, p.1276-1282

$\overline{\text { Manuscript received: 9.12.2019 }}$ 